\title{
Direito a resistir ao direito? A atuação judicial no caso da ocupação Raízes da Praia em contexto de violação aos direitos fundamentais
}

\author{
Right to resist the law? The judicial action at Raízes \\ da Praia occupation in a context of fundamental rights \\ violation
}

\author{
Natalia Martinuzzi Castilho* \\ Gustavo Raposo Pereira Feitosa*
}

\section{Resumo}

Este artigo trata do estudo do significado jurídico-político do fenômeno da resistência à decisão judicial a partir da experiência de uma ocupação urbana organizada pelo Movimento dos Conselhos Populares (MCP), na cidade de Fortaleza, Ceará. O estudo envolveu uma pesquisa de caráter bibliográfico na literatura científica de referência, documental e de campo. A pesquisa de campo ocorreu durante os meses de abril e maio de 2011 na ocupação Raízes da Praia, em que se analisou a postura do Poder Judiciário no conflito e a forma como a resistência emergiu como elemento fundamental para a efetivação do direito à moradia das famílias envolvidas. A análise da intervenção do Poder Público e do Judiciário no caso destaca o estudo da resistência à decisão judicial como alternativa extrema para aqueles que sofrem cotidianamente

Mestrado (2013) pela Universidade do Vale do Rio dos Sinos (UNISINOS). Professora de direito do Centro Universitário Christus. Coordenadora do Escritório de Direitos Humanos, Direito Ambiental e Assessoria Jurídica Popular (EDH). Integrante do Instituto de Pesquisa Direitos e Movimentos Sociais (IPDMS). Fortaleza - CE - Brasil. E-mail: natiimc@gmail.com

* Possui graduação em Direito pela Universidade Federal do Ceará (1997), mestrado em Sociologia pela Universidade Federal do Ceará (2000) e doutorado em Ciências Sociais pela Universidade Estadual de Campinas (2005). Atualmente é professor Titular do Programa de Pós-Graduação em Direito Constitucional - Mestrado e Doutorado - e do Centro de Ciências Jurídicas da Universidade de Fortaleza. É professor adjunto de Direito Processual Civil na UFC. Coordena o Mestrado Profissional em Direito e Gestão de Conflitos da Universidade de Fortaleza. ). Fortaleza - CE - Brasil. E-mail: gfeitosa@terra.com.br 
violações de direitos, muitas vezes utilizada por causa da ineficácia dos recursos institucionais.

Palavras-chave: Resistência. Poder Judiciário. Democracia. Movimentos populares.

\section{Abstract}

This article studies the legal and political significance of the resistance phenomenon to court decisionfrom the experience of an urban occupation organized by the People's Councils Movement (MCP) in the city of Fortaleza, Ceará, Brazil. The study occurred by a bibliographical, documental and field research. The fieldwork took place during the months of April and May 2011 in the occupation "Raizes da Praia", and examined the judicial processand the way the resistance has emerged as a key element for the realization of housing rights of families involved. The analysis of government and judicial intervention in this conflict highlights the study of resistance to the court decisions as an extreme alternative of those who daily suffer rights violations, often used in a context of ineffective institutional resources.

Keywords: Resistance. Judicial Power. Democracy. Popular movements.

\section{Introdução}

Embora geralmente não abordados no estudo regular do direito, os atos e movimentos de resistência à ordem jurídica institucional, de âmbito individual ou coletivo, apresentam elementos importantes para a compreensão do fenômeno jurídico. As ações individuais de desobediência aos atos ilegítimos, arbitrários ou tirânicos do Estado, ou mesmo as iniciativas coletivas organizadas em torno de reivindicações por novos direitos, oferecem relevantes oportunidades para se analisar as relações entre o direito e a política nas democracias contemporâneas.

Como pano de fundo para a reflexão sobre o fenômeno da resistência, analisou-se a experiência da comunidade Raízes da Praia, que surgiu mediante a ocupação organizada pelo Movimento dos Conselhos Populares (MCP) em um terreno abandonado na região 
conhecida como Praia do Futuro, na cidade de Fortaleza (Ceará - Brasil), no ano de 2009. Buscou-se compreender a importância da resistência no processo de luta pelo direito à moradia e à terra urbana. Por meio de pesquisa de campo, realizada entre os meses de abril e maio de 2011, discutiu-se os elementos contraditórios da atuação jurisdicional no caso e os motivos da resistência da comunidade. Esses aspectos forneceram subsídios para a reflexão acerca da possível legitimidade da resistência diante dos conflitos sociais que permeiam a realidade jurídica.

$\mathrm{Na}$ tentativa de rompimento com a perspectiva liberal que historicamente predomina no estudo sobre o tema, busca-se a retomada do debate em torno do direito de resistência a partir da realidade social, econômica e política de países latino-americanos, como o Brasil, nos quais a resistência apresenta-se também como um mecanismo de concretização de direitos fundamentais por sujeitos políticos organizados em movimentos populares ${ }^{1}$. Em segundo plano, busca-se ainda identificar as consequências positivas ou negativas, bem como os aspectos contraditórios da intervenção do Poder Judiciário, mediante a judicialização desses conflitos sociais.

\footnotetext{
Acerca do conceito de movimento popular e seus traços distintivos em relação aos movimentos sociais, Pazello (2010, p. 295) esclarece: "Movimentos populares (ao invés de sociais) devem ser entendidos a partir de uma perspectiva total, não podendo vincular suas lutas, de forma absoluta, a uma necessidade específica. Quer dizer, na organização política popular há várias necessidades a serem satisfeitas (por vários satisfatores). É certo, ainda, que as organizações costumam eleger uma necessidade (ou violência/opressão específica) e erigir sua bandeira sobre essa especificidade. É o caso, no contexto brasileiro, das mulheres, dos negros, dos estudantes, dos crentes, dos ecologistas, dos pacifistas, dos homossexuais e assim por diante. Esse também é o caso dos sem-terra, dos sem-teto, dos atingidos por barragens, dos indígenas, dos quilombolas, dos pescadores, dos camponeses explorados, dos trabalhadores aviltados e muitos etcétereas. Ocorre que entre um grupo e outro de organizações políticas populares (ou movimentos sociais, abarcando-se as não-organizações) há uma diferença bastante incisiva, ao menos ainda não ultrapassada no estágio atual das lutas sociais: no primeiro caso, elege-se uma opressão específica (machismo, preconceito racial, educação bancária...) e, no segundo, também (falta de terra, de teto, de casa) com o adendo de que neste último o primeiro está potencialmente incluído.".
} 


\section{A atualidade do fenômeno da resistência: breves apontamentos desde a tradição liberal}

As relações (e reações) entre a sociedade e o poder instituído se manifestam, analisando-se o percurso da história oficial, desde as primeiras formas de organização política². A luta dos povos contra opressões de variados matizes diz muito sobre as origens do dever de obediência à autoridade e ao poder político. Tais lutas não se deram somente a partir de atos individuais de desobediência às leis do Estado, mas também de resistências coletivas, organizadas ou desorganizadas, espontâneas e até mesmo institucionais. As manifestações filosóficas e políticas mais rebuscadas e consistentes acerca dos limites e possibilidades de resistir a regimes ou leis consideradas injustas se expressam, principalmente, a partir da formação do conceito de Estado liberal.

O desenvolvimento da doutrina liberal forneceu as bases para o surgimento da concepção do direito de resistência no direito estatal ocidental e, indiretamente, no sistema jurídico dos países conquistados a partir da dominação colonial, ou seja, no sistema jurídico-político dos países colonizados, como o Brasil. O surgimento do liberalismo e o aprofundamento das relações sociais de compra e venda determinou o desenvolvimento das relações econômicas e políticas, que, por sua vez, indicaram as bases do pensamento jurídico ocidental nascente.

As revoluções liberais burguesas estabeleceram tal consolidação por meio de embates que possibilitaram a ascensão da burguesia ao

\footnotetext{
As produções do pensamento antigo e medieval revelam-se de grande influência para a delimitação do direito de resistência na modernidade. Apesar de não constituir o objetivo deste trabalho, destaca-se a importância das reflexões da Antiguidade Clássica, especialmente em Sófocles, em Antígona, Platão e Sócrates. Essas principais manifestações de pensamento características da Grécia Antiga, levam à consideração de que, para os gregos, a crença no direito natural e divino determina os limites da obediência ou não às leis do soberano. Destacam-se também os debates formulados por Tomás de Aquino. Na doutrina tomista os governantes devem proteger diretamente o bem comum, a ordem social. Desfeito o acordo entre o povo e o soberano, os súditos sublevam-se na defesa da comunidade, que sofre a destruição de seus princípios mediante a injustiça dos atos tirânicos. Se essa resistência, passiva ou ativa, dependendo do ato do tirano, não logra sucesso, cabe ao povo então esperar obter de Deus a punição do tirano. Ver mais em: Sófocles (2008, p.20); Paupério (1978, p. 66); Bobbio e Gianfranco (1998, p. 372).
} 
poder político e o "coroamento" do modo capitalista de produção na Europa. Nesse sentido, a institucionalização dos direitos dos indivíduos frente ao Estado surge como tema fundamental nas teorias sobre o Estado moderno, e representaram um importante aporte teórico, capaz de destacar o lugar e a importância do conceito de direito de resistência para a sociedade ocidental.

As bases para o desenvolvimento da teoria contratualista ${ }^{3}$ encontram-se nesta linha de raciocínio, por isso, destaca-se o contratualismo na construção de uma teoria política capaz de superar a supremacia dos regimes despóticos que dominavam todas as esferas da vida dos súditos, principalmente a econômica. John Locke (1988), autor central do liberalismo político, situa a instituição do direito de resistência como um direito fundamental tão indispensável quanto à defesa da propriedade. O direito de resistência, assim, limitava-se àqueles que detêm algum tipo de propriedade e que podem reivindicar o pleno exercício da mesma. Qualquer medida do Estado contrária aos interesses, não desses indivíduos, mas do cidadão entendido como detentor do direito de propriedade, poderia sofrer objeção, tendo em vista que o "contrato social" teria surgido com o objetivo maior de proteção da liberdade e segurança desses (LOCKE, 1998, p. 24).

No contexto da linha evolutiva do Estado Moderno, referenciada na história europeia ocidental, os direitos do homem passam a ser vivenciados gradualmente de forma material, expandindo as fronteiras dos direitos civis e políticos. Também devido a esse quadro, a tradição de um poder centralizador e autoritário transformou-se em estruturas de

\footnotetext{
Para Bobbio (1998, p. 272), em sentido muito amplo, o Contratualismo compreende todas aquelas teorias políticas que vêem a origem da sociedade e o fundamento do poder político (chamado, quando em quando, potestas, imperium, Governo, soberania, Estado) em um contrato, isto é, um acordo tácito ou expresso entre a maioria dos indivíduos, acordo que assinalaria o fim do estado natural e o início do estado social e político. Num sentido mais restrito, por tal termo se entende uma escola que floresceu na Europa entre os começos do século XVII e os fins do XVIII e teve seus máximos expoentes em J. Althusius (1557-1638), T. Hobbes (1588-1679), B. Spinoza (16321677), S. Pufendorf (1632-1694), J. Locke (1632-1704), J.-J. Rousseau (1712-1778), I. Kant (17241804). Por escola entendemos aqui não uma comum orientação política, mas o comum uso de uma mesma sintaxe ou de uma mesma estrutura conceitual para racionalizar a força e alicerçar o poder no consenso.
} 
uma democracia política. Isso pôde ser verificado com o fortalecimento da sociedade civil, o que também contribuiu para o crescimento de uma política cultural democrática no Ocidente (MUZAFFAR, 1999, p. 26).

O modelo constitucional dos Estados contemporâneos comporta, nesse sentido, uma ampla gama de contradições, na medida em que afirma um rol extenso e complexo de direitos - porque vão muito além das garantias individuais de liberdade e propriedade - mas, ao mesmo tempo, convive com contextos de violações institucionais de direitos humanos. Um exemplo claro desse tipo de dicotomia pode ser encontrado nas relações e tensões existentes entre a absolutização do direito de propriedade e a necessidade de concretização do direito à moradia de milhares de pessoas, organizadas ou não em movimentos sociais. Conforme analisado na pesquisa aqui sintetizada, muitas vezes, as possibilidades de efetivação do direito à moradia chocam-se frontalmente com a tradição do exercício do direito de propriedade em nossa sociedade, que pode ser entendida como visceral e historicamente conectada à concentração de renda e à especulação imobiliária em detrimento da democratização do acesso à terra urbana.

$\mathrm{O}$ ato de resistir à uma ordem judicial e ao direito formalmente estabelecido, nesse contexto, encontra-se relacionado às dicotomias e contradições que a realização do Direito implica nas relações sociais no contexto de sociedades desiguais. Tal resistência, quando forjada no interior de processos sociais que evidenciam uma situação de grave violação de direitos humanos e fundamentais, deve ser considerada pelo ordenamento jurídico como um movimento necessário e urgente para seu próprio desenvolvimento, desde que se considere em tal ordem a existência de algum horizonte democrático.

\section{Legalidade e ilegalidade na resistência à ordem judicial e a atuação do Poder Judiciário: a experiência da ocupação Raízes da Praia}

O breve relato desta experiência tem origem no trabalho de campo realizado entre os meses de abril e maio de 2011. A observação 
participante, a realização de entrevistas por meio de um questionário semi-estruturado e a leitura de documentos da comunidade foram os métodos capazes de traçar a síntese da história de luta por moradia das famílias organizadas no Movimento dos Conselhos Populares (MCP) e de suas visões acerca do significado da resistência ao ordenamento jurídico.

A comunidade Raízes da Praia ${ }^{4}$ surgiu em julho de 2009. Nasceu de uma ocupação urbana realizada por oitenta famílias sob a coordenação do $\mathrm{MCP}^{5}$. A organização e o desejo de promover essa ocupação surgiram três anos antes, do encontro de famílias despejadas violentamente de uma ocupação frustrada, também em um terreno na Praia do Futuro, com militantes do MCP que atuavam naquela região. Após esse encontro, iniciaram-se reuniões que congregavam cerca de 200 pessoas, organizadas em torno do objetivo de alcançar o sonho da moradia digna. A partir dessas reuniões, foram encaminhados diversos

4 A comunidade situa-se na cidade de Fortaleza-CE (Brasil), em um terreno na região da Praia do Futuro, entre as Avenidas César Cals, ao sul e Zezé Diogo ao norte, ao oeste pela Rua Prof. Murilo Silveira e ao leste pela Rua Doutor Antônio Carneiro. Cabe-se destacar que, de acordo com os relatos dos advogados entrevistados, o imóvel constitui-se como propriedade da União, pois está situado na faixa de praia a uma distância capaz de enquadrá-lo como terreno de marinha.

5 O MCP - Movimento dos Conselhos Populares é um movimento popular que surgiu no ano 2000, a partir do processo de eleições municipais que agregou vários partidos de esquerda em uma única candidatura. Nesse primeiro momento, o Movimento não conseguiu se consolidar e acabou findando em 2003. Em abril de 2005, existe uma refundação do Movimento, impulsionada pela vitória eleitoral do Partido dos Trabalhadores nas eleições municipais e pela realização da $1^{\text {a }}$ Assembléia Popular da Cidade. Em uma plenária, conhecida como a Plenária da Cidade, promovida pelo MCP em abril de 2008 , o movimento define uma atualização de seu programa e uma nova estrutura organizativa. Neste momento, também, o movimento passa a discutir mais intensamente a pauta da luta por moradia. O movimento surge com a proposta de construção de Conselhos Populares, espaços organizativos nos bairros através dos quais o povo seja capaz de construir formas de lutar coletivamente por suas demandas, sem esperar que um poder externo as concretize. Atualmente o movimento trabalha com diversas frentes inseridas em eixos organizativos centrais, que são a cidade, o trabalho e a cultura. Dentro do eixo "cidade", que consiste na luta mais ampla pelo direito à cidade, está inserida a discussão sobre a falta de moradia, a urbanização as áreas periferias, a utilização e apropriação dos recursos naturais e culturais do espaço urbano, etc. A resistência é o principal instrumento de ação do movimento, através de mobilizações e, nesse momento mais atual, de organização de ocupações de terra. Pela forma como a expansão do capital se deu na cidade de Fortaleza, o movimento passou a atuar mais fortemente através de atos de resistência. (SOUSA, 2011, p. 99). 
atos reivindicatórios ao poder público municipal: ofícios, abaixoassinados, representações, mobilizações, passeatas e reuniões oficiais. Conforme relata uma das coordenadoras do movimento:

Fazíamos reuniões aos sábados, mandava oficio à Fundação Habitacional de Fortaleza (HABITAFOR). A gente começou, grupos iam pra HABITAFOR, outros iam pra onde fosse procurando uma solução pro problema daquelas pessoas que ficaram a ver navios, que foram derrubados os casebres, pessoas que gastaram comprando madeira, as tábuas, e ficaram todo mundo desgarrado. E foi no percurso né, reunião, manifestação, enviava comunicado, e a prefeitura levando a gente só em banho-maria. Nessa história de vai-vai, que eles nunca fizeram nada, foi que a gente já tava no pescoço, o sangue já tava a mil. Foi o tempo que a gente começou a se reunir, coordenação e MCP e a gente chegou ao extremo de dizer assim, 'vamo procurar terra'[...]. (SIC). ${ }^{6}$

Diante da inércia do Poder Público, ocupar a terra representou o último recurso para as famílias. O terreno ocupado encontrava-se abandonado há mais de 25 anos, conforme o relato dos moradores e militantes do Movimento. No dia da ocupação, 03 de julho de 2009, as tentativas de despejo iniciaram-se de maneira ilegal, mediante a contratação, pelo proprietário ${ }^{7}$ do terreno, de um grupo de homens armados, alguns oriundos da Polícia Militar, conforme se comprovou

6 Entrevistada "F.", membro da coordenação do Movimento dos Conselhos Populares. Entrevista concedida em 2 de maio de 2011.

7 Posteriormente, a polícia confirmou que três integrantes do grupo trabalhavam como policiais militares e estavam em estágio probatório para se tornarem policiais do programa Ronda do Quarteirão. Autuou-se por agressão somente um deles (O ESTADO, 2009, on-line). O Ronda do Quarteirão constitui-se em um instrumento da política de policiamento do Governo do Estado do Ceará no ano de 2007. Inspirado no conceito de policiamento comunitário e na aproximação da relação entre comunidade e polícia civil, o projeto Ronda do Quarteirão destina unidades de policiamento móvel para cada bairro da cidade. Apesar da motivação "humanista", a experiência na cidade de Fortaleza mostra efeitos contrários e muito graves, pois são diversos os casos de denúncias de policiais do Ronda por agressão e, principalmente, abuso de autoridade. 
posteriormente ${ }^{8}$, e outros empregados de empresas de segurança. $O$ grupo permaneceu dia após dia no terreno, intimidando e agredindo os moradores, e impedindo a realização de melhorias na estrutura do lugar.

Conforme o relato dos advogados da comunidade, em um primeiro momento, o proprietário quis evitar a judicialização do conflito. Tratavase, então, de retirar a população a qualquer custo, e de preferência à margem da lei. Ao perceber a organização do Movimento e o seu poder de articulação com várias entidades de direitos humanos da cidade, a assessoria jurídica do proprietário resolveu ingressar com a ação de reintegração de posse. Restou clara a vontade de não recorrer ao Poder Judiciário mediante a recusa da utilização de meios legais para a afirmação do seu direito.

O enfrentamento dos limites da legalidade pelas famílias, neste caso, impôs a "legalização" da ação do proprietário. A força da resistência das famílias às primeiras investidas violentas levou o conflito ao alcance do Poder Judiciário. Infere-se que, se as famílias não resistissem às primeiras ameaças, nada aconteceria ao proprietário e aos envolvidos na ação ilegal de expulsão daquelas pessoas. Nesse contexto, a observância ou não da ordem legal não se encontra centrada unicamente no ato de ocupação realizado pelas famílias. Verificou-se que os meios utilizados pelo proprietário do terreno foram escusos e flagrantemente ilegais, pois as tentativas de expulsão das pessoas se deram mediante a contratação de homens armados, que ameaçaram de morte os participantes da ocupação durante vários dias. Pode-se afirmar que a defesa do discurso de legalidade, portanto, é construída no limiar

8 Posteriormente, a polícia confirmou que três integrantes do grupo trabalhavam como policiais militares e estavam em estágio probatório para se tornarem policiais do programa Ronda do Quarteirão. Autuou-se por agressão somente um deles (O ESTADO, 2009, on-line). O Ronda do Quarteirão constitui-se em um instrumento da política de policiamento do Governo do Estado do Ceará no ano de 2007. Inspirado no conceito de policiamento comunitário e na aproximação da relação entre comunidade e polícia civil, o projeto Ronda do Quarteirão destina unidades de policiamento móvel para cada bairro da cidade. Apesar da motivação "humanista", a experiência na cidade de Fortaleza mostra efeitos contrários e muito graves, pois são diversos os casos de denúncias de policiais do Ronda por agressão e, principalmente, abuso de autoridade. 
de interesses conflituosos, que envolvem o grau de poder econômico e político dos sujeitos que se organizam na sociedade.

A atuação do Movimento pautou-se pela pressão e, ao mesmo tempo, por um diálogo constante com o Poder Público municipal. Nesse sentido, nos primeiros dias após a ocupação, abriu-se uma mesa de negociação da qual se extraiu uma vitória parcial para as famílias e para o Movimento: a desapropriação, por parte da Prefeitura, de um dos lotes do terreno. Esse fato significou uma atuação inédita do Poder Público, tendo em vista que, nos casos de ocupações urbanas em terreno particulares, o órgão responsável pela política de habitação eximiase de quaisquer responsabilidades, alegando ser competente apenas nos casos de ocupações de imóveis públicos. A resistência favoreceu a aplicação de novos mecanismos institucionais capazes de viabilizar a efetivação do direito à moradia, da forma como este significava, naquele contexto, para os integrantes do movimento social (MCP) e para a comunidade que ali já se formava.

A negociação realizada no âmbito extrajudicial, entretanto, não repercutiu na atuação do Poder Judiciário em relação ao conflito. Mesmo após a expedição do decreto de desapropriação, a magistrada responsável emitiu a liminar de reintegração de posse. Esta atitude gerou um impasse na relação entre a Administração e o Judiciário, tendo em vista que a desapropriação da área deveria surtir efeitos sobre a análise da medida judicial de reintegração. Tal contradição mostrou-se positiva, porque pôde criar uma força de transformação da forma tradicional com que o Judiciário atua no tocante ao direito de propriedade e às formas de efetivação do direito à moradia. A decisão política do município, de certa maneira, forçou o Poder Judiciário a modificar, ainda que devido a essa intervenção externa, a forma privatista e conservadora com que lidou com o conflito.

Apesar da crença no seu direito fundamental à moradia e de almejar o reconhecimento estatal de suas demandas, os moradores percebiam com clareza que a ocupação do terreno e a resistência à 
ordem judicial significaram uma transgressão. Nas palavras de uma moradora:

Eu me senti assim. Desobedecendo, entrando em um canto que não era da gente. Mas como tem muita gente que não tem onde morar, com o incentivo dos outros eu aproveitei e entrei também, que eu também não tinha. Morava nesse barraco onde foi mordido de rato eu, meus dois meninos, meu marido, tudo foi mordido de rato. $\mathrm{E}$ a gente entremo aqui porque muita gente precisava também e muita gente pediu socorro né, que não tinha onde morar, ai a gente aproveitemo. Mas eu me senti assim, invadindo um ambiente que não era pra ser.

Mas a senhora acha que vocês têm direito a estar aqui?

Por um lado eu acho que sim, porque muita gente que precisa né, que morava com família. Eu era uma que morava com meus pais, depois de passar um tempo com a mãe do meu marido, a gente sofre muito, eu agüentei muita humilhação, tanto eu da família dele como ele da minha família. Uma coisa meia, sem direito, sem permissão de a gente entrar no ambiente alheio, mas tamos aqui né, foi o jeito. (SIC) ${ }^{9}$

Vê-se a resistência como um ato de transgressão, mas legitimado pelo estado de necessidade vivenciado por ela e pelas demais famílias que participaram da ocupação. Ao afirmar que "foi o jeito", a moradora traduz a descrença na possibilidade de atuação do Poder Público na solução do problema do déficit habitacional na região. Nota-se, por esta passagem, o entendimento de que a ocupação consistiu em um ato extremo, que causou resistência inicial para os próprios envolvidos, mas que representou a única alternativa, apesar de refletir uma iniciativa contrária a seus conceitos pessoais de justiça e moralidade. Reconheciase que a violação do direito à propriedade de outrem - na forma como esse direito estava "sendo exercido", sem a utilização social do imóvel

$9 \quad$ Entrevistada S., moradora da comunidade. Entrevista concedida em 30 de abril de 2011. 
- representava um impacto menor frente à continuidade da situação de extrema vulnerabilidade daquelas oitenta famílias.

Essas considerações, somadas às tentativas ilegais de despejo e à violação institucional do direito à moradia dessas e de outras inúmeras famílias, refletem de que maneira a desigual disposição do poder político e econômico na sociedade influencia as possibilidades de efetivação da ordem jurídica.

\section{A potencialidade do fenômeno da resistência para o desenvolvimento da justiça social e da democracia na sociedade}

Para que se possa compreender verdadeiramente o papel da resistência, os atos desenvolvidos por movimentos populares, como o caso analisado neste trabalho, devem ser observados não a partir da lógica liberal do direito de resistência, mas segundo sua potencialidade em fornecer alternativas às desigualdades estruturantes em sociedades periféricas, como a brasileira, pressionando as estruturas de poder, institucionalizadas ou não, frente à necessidade de concretização de uma ordem democrática pautada pela justiça social. O confronto entre a normatividade garantidora de direitos fundamentais e a realidade concreta brasileira demanda a rediscussão sobre as possibilidades do direito de resistência como mecanismo de ampliação do princípio democrático a partir da ordem constitucional inaugurada em 1988.

O estado de necessidade constituiu-se como elemento que motivou a participação das famílias na ocupação. O sentido dessa necessidade pode ser identificado a partir da condição insustentável de vida a que estavam submetidos, constituindo-se em vítimas das falhas do ordenamento jurídico vigente (DUSSEL, 2006, p. 85):

Víctimas, porque no pueden vivir en el grado relativo a la evolución histórica de la humanidad; víctimas que de alguna manera se encuentran en asimetría en la participación, o simplemente han sido excluidas de la misma. En fin, el orden 
político manifiesta por sus víctimas - en cuanto no puede distribuir a todos los beneficios del orden vigente. Desde las víctimas, cuando el sufrimiento se hace inaceptable, intolerable, surgen movimientos sociales contestatarios en el campo político empírico.

Discute-se, mediante a resistência da comunidade Raízes da Praia, como funcionam as formas de concretização da justiça não somente pelo Poder Público, mas também pelo Judiciário. A resistência e suas diferentes manifestações nesse conflito apontam divergências a respeito das prioridades do Estado e do Poder Judiciário no que tange à concretização de direitos humanos. Coloca-se em cheque a efetividade da própria estrutura organizativa do sistema jurídico-político por meio da busca em se conferir factibilidade a direitos garantidos na Constituição ${ }^{10}$, que, por não serem efetivamente aplicados, podem representar diferentes interesses a partir de diferentes discursos.

A complexidade dos processos sociais direciona o sentido da efetividade da Constituição que, por ter sido construída em um ambiente plural, continua sendo palco de disputas e contradições. Em um país com níveis elevados de pobreza e desigualdade social, o processo de materialização dos direitos fundamentais não existe sem enfrentamentos e conflitos entre os setores e classes sociais entre si, e entre estes e o Poder Judiciário, tendo em vista que os órgãos institucionais não se encontram isolados dos fenômenos e interações sociais.

10 O próprio processo de elaboração de texto constitucional e de concretização material da Constituição Federal de 1988 reflete-se na emergência de objeções coletivas ao ordenamento jurídico em casos de conflitos originados pela contradição entre grandes proprietários de terra e a população sem moradia digna, que deriva, por sua vez, da oposição mais complexa entre capital e trabalho, que condiciona o modo de produção da sociedade moderna. As oposições e resistências ocorrem em várias vertentes. A resistência não se revela um recurso exclusivo de grupos vulneráveis e pobres. Grandes proprietários de terra utilizam-se vigorosamente de todos os meios ao seu alcance (legais e, por vezes ilegais) para resistir à aplicação de instrumentos que se amparam na concepção de função social da propriedade, obstaculizando rotineiramente iniciativas estatais lícitas e formalmente irretocáveis. 
Nesse aspecto, aponta-se a necessidade de discussão sobre o papel da resistência hoje, principalmente porque são muitos os elementos da prática judiciária que, em uma postura mais extrema e conservadora, criminalizam a resistência ou a julgam desnecessária e perniciosa. Revela-se crescente a tendência muitas vezes repressora e antidemocrática do Poder Judiciário em relação à resistência quando essa ocorre a partir da atuação de movimentos populares. O processo de perseguição e criminalização de atos de resistência realizados por este segmento representa a diferença entre o discurso e a práxis constitucionais. No caso analisado, em nenhum momento a atuação judiciária considerou o aspecto social das motivações das famílias em ocupar o terreno. Afastou-se sobremaneira da leitura constitucional em relação à proteção ao direito à moradia e à responsabilidade do Estado em garantir sua efetivação.

A evolução do conceito e da importância da democracia na Constituição brasileira representa uma consequência da atuação política do povo, que, muitas vezes, por meio da resistência à ordem jurídica, não desistiu de se organizar para a efetivação de suas demandas, como consequência direta disso, para a construção de um sistema jurídico-normativo orientado pela concretização da justiça social. Tal direito à resistência pode ser concebido juridicamente, como afirma José Carlos Buzzanello (2006), a partir da interpretação dos princípios constitucionais, tendo em vista que a resistência não pode ser tomada somente como fato político, por pertencer a um universo teórico mais abrangente, que envolve também a seara jurídica.

A partir da leitura de Maria Garcia (2004), torna-se possível construir a interpretação, por meio do disposto no $\$ 2^{\circ}$, artigo $5^{\circ}$, de outras modalidades do direito de resistência a partir do modelo social da Constituição de 1988, mais especificamente a desobediência civil. Esse dispositivo constitucional confere guarida aos princípios "implícitos", que decorrem da própria valoração constitucional, dos seus objetivos descritos no artigo primeiro, ou dos que venham a constar em tratados internacionais. 
Os métodos de efetivação de direitos fundamentais, quando não impelem a destruição do próprio Estado, mediante atos de resistência armada, por exemplo, podem ser admitidos pelo ordenamento como expressões do direito de resistência, entendido como forma de efetivação da cidadania e do princípio democrático. Conforme se verificou no estudo do caso concreto, em vários momentos os moradores identificaram-se como "cidadãos" lutando por seus próprios direitos. 0 conceito de cidadania incorpora, além do papel político dos sujeitos em relação à coisa pública e aos direitos e deveres na relação ao Estado, a noção de que os indivíduos são sujeitos de direitos, e que os direitos constitucionalmente garantidos ganham efetividade somente a partir da significação que aqueles conferem ao direito postulado.

O direito fundamental à moradia, no caso analisado, tornou-se um exemplo disso. Deu-se como efetivado para aquelas famílias a partir de um ato de resistência, e esse ato concebeu o significado desse direito para as pessoas que sofriam esse tipo de violação, bem como para o próprio Poder Público, que foi forçado a concretizar novos instrumentos político-jurídicos para garantir a sua efetivação naquele caso concreto. A resistência oferece mecanismos para o próprio sentido de existência da democracia, pois se denota no discurso e na teoria democrática a tendência a uma radicalidade, expressa por meio da busca pela efetivação da autonomia popular e pela inserção cada vez maior dos indivíduos e setores sociais nos processos políticos.

O Estado Democrático de Direito consolidou sua legitimidade principalmente a partir do que Habermas (2010, p. 197) define como interação entre autonomia privada e autonomia pública. Essa autonomia gerada no seio da movimentação coletiva reflete-se no modo de funcionamento do sistema jurídico-político, porque os indivíduos passam a se identificar como sujeitos e autores do próprio direito. Segundo o autor, do ponto de vista normativo, não pode haver Estado de Direito sem democracia. Um Estado que se afirme como garantidor de direitos fundamentais capazes de preservar a equiparação jurídica, social e econômica dos cidadãos e o reconhecimento de grupos que se diferenciam culturalmente por sua tradição, modo de vida, etnia etc. não 
pode subsistir sem uma ordem jurídica efetivamente democrática, capaz de respeitar as possibilidades de resistência, como a evidenciada neste estudo.

Diante do pensamento habermasiano, questiona-se o fato de que, nas sociedades periféricas, os grupos sociais oprimidos não conseguem construir, em sua práxis, o sistema jurídico-normativo estatal. As desigualdades econômicas e sociais os lançam, na maior parte das vezes, para fora dos processos de decisão e de formação dos consensos majoritários, nos campos jurídico e político especialmente.

Na busca pela materialização do princípio democrático, as disputas relativas às prioridades do sistema jurídico-político podem emergir e o poder estatal pode ser influenciado mediante a intervenção popular ${ }^{11}$. Enquanto o regime democrático atual não aprofunda os mecanismos de participação e intervenção direta da sociedade no poder político do Estado, serão necessários atos de resistência para que a população construa uma lógica de efetivação, e não de supressão de direitos fundamentais. A resistência no caso analisado estabeleceu as condições de produção legítima do direito originadas da atuação popular. Quando o reconhecimento dos direitos básicos da população não ocorre, ou mesmo quando os meios reconhecidos ou institucionalizados não se mostram suficientes para a concretização das reivindicações populares, a resistência ao ordenamento jurídico legitima-se como expressão democrática da soberania popular (GARGARELLA, 2005).

Este ponto de conexão se expressa na compreensão de que, no Estado Democrático de Direito, a divisão de papéis entre os que legislam e os destinatários do direito vigente deve ser reconsiderada para que se amplie a concretização dos direitos fundamentais garantidos constitucionalmente. A falência de todas as formas legais

11 Todas las instituciones, todos los sistemas institucionales, a corto, mediano o largo plazo deberán ser transformadas. No hay sistema institucional imperecedero. Toda la cuestión es saber cuándo debe continuar una institución, cuando es obligatoria una transformación parcial, superficial, profunda o, simplemente, una modificación total, de la institución particular o de todo el sistema institucional. (DUSSEL, 2006, p. 126) 
para a concretização do direito à moradia reflete o "descompasso", ocasionado pelo conflito de classes, entre a atuação dos que legislam e dos destinatários do direito vigente. Tal "descompasso" ensejou o enfrentamento, dos ocupantes e do próprio movimento, à ordem jurídica - decisão judicial de reintegração de posse. No entanto, mediante o processo de resistência, criaram-se novos mecanismos, no âmbito do Poder Público, para a solução do problema da moradia daquelas pessoas. Na perspectiva de resistência inserida no âmbito da legalidade, seu exercício constitui-se como ferramenta legítima de efetivação de um princípio normativo capaz de orientar a ação dos sujeitos que atuam no sistema político. Um ambiente plural que garanta a aplicabilidade do princípio democrático mostra-se determinante para a constituição de modelos institucionais cada vez mais radicais na perspectiva de efetivação dos direitos fundamentais.

\section{Conclusão}

As situações de resistência ao direito analisadas revelam que a noção de direito de resistência exerce papel essencial, no debate político e plural da democracia, para efetivação dos direitos fundamentais, mediante a exigência de uma postura mais ativa do Poder Público nos casos de extremos de ausência de mecanismos legais ou institucionais de afirmação e concretização dos mesmos.

No caso da luta por moradia da ocupação Raízes da Praia, a dicotomia entre o direito de moradia reivindicado pelas famílias e a manutenção do direito de propriedade sem o exercício da função social por mais de 25 anos refletiu-se nos ambitos de atuação do Poder Público e do Judiciário. A resistência das famílias à ordem judicial de reintegração de posse, emitida apesar da negociação extrajudicial, foi capaz de revelar as ilegalidades cometidas pelo proprietário, denunciando situações muitas vezes negligenciadas pelo Judiciário no caso de conflitos sociais dessa natureza. A organização e a resistência foram responsáveis, ainda, pela formulação de um novo mecanismo para a resolução de conflitos urbanos, pois, por meio da pressão social, 
o município efetivamente desapropriou a área particular, fato inédito na cidade.

O direito de resistência ao direito pôde ser concebido neste trabalho como uma forma de atuação legítima dos movimentos populares na concretização do princípio democrático e do pluralismo político, que fundamentam o modelo constitucional. A resistência foi considerada, ainda, como uma forma de possibilitar processos de conscientização popular e de efetivação radical e direta de direitos fundamentais. 0 exercício da resistência em casos extremos pode representar, nesse sentido, uma forma de concretização dos objetivos e princípios da ordem jurídica democrática na medida em que enfrenta diretamente e propõe alternativas reais aos principais obstáculos para a vivência efetiva da cidadania pelos oprimidos.

\section{Referências}

BOBBIO, Norberto; MATEUCCI, Nicola e GIANFRANCO, Pasquino. Dicionário de Política. 11. ed. Brasília: UNB, 1998.

BUZANELLO, José Carlos. Direito de resistência constitucional. 2. ed. Rio de Janeiro: Lumen Juris, 2006.

DUSSEL, Enrique. 20 tesis de politica. 2. ed. Mexico: Siglo XXI: Centro de Cooperación Regional para La Educación de Adultos en América Latina e Caribe, 2006.

HABERMAS, Jürgen. La inclusióndelotro:estudios de teoría política. 4. ed. Espanha: EdicionesPaidós Ibérica, 2010.

GARCIA, Maria. Desobediência civil: Direito Fundamental. 2. ed. rev. atual. e ampliada. São Paulo: Revista dos Tribunais, 2004.

GARGARELLA, Roberto. El derecho a resistir elderecho. Buenos Aires: Mino y Dávila, 2005.

GIRÃO, Ivna. Raízes da Praia denunciam PM por integrar milícias. Jornal O Estado, Fortaleza, 29 jul. 2009. Disponível em: <http://www. 
oestadoce.com.br/index.php?acao=noticias\&subacao=ler_noticia\&cad ernoD=22\&noticialD=15085> Acesso em: 25 maio 2011.

LOCKE, John. Segundo Tratado sobre o Governo: Ensaio relativo à verdadeira origem, extensão e objetivo do Governo Civil. São Paulo: Martin Claret, 2009.

MARSHALL, T. H. Cidadania, classe social e status. Rio de Janeiro: Zahar, 1967.

MUZAFFAR, Chandra. From human rights to human dignity. In: VAN NESS, Peter. Debating human rights: critical essays from the United States and Asia. London: Routledge, 1999. p. 25-31.

PAUPÉRIO, A. Machado. O direito político de resistência. 2. ed. rev. e ampliada. Rio de Janeiro: Forense, 1978.

PAZELLO, Ricardo Prestes.A produção da vida e o poder dual do pluralismo jurídico insurgente: ensaio para uma teoria de libertação dos movimentos populares no choro-canção latino americano.

Dissertação de Mestrado do Programa de Pós-Graduação em Direito da Universidade Federal de Santa Catarina (UFSC). Disponível em: <www.scribd.com/Ricardo2p/documents>. Acesso em: 25 fev. 2011.

PROGRAMA DAS NAÇÕES UNIDAS PARA O DESENVOLVIMENTO. Relatório sobre o Desenvolvimento Humano do Programa das Nações Unidas para o Desenvolvimento (PNUD).Disponível em: <http://hdr.undp.org/statistics/data/pdf/hdr04_table_14.pdf> Acesso em: 23 maio 2011.

SÓFOCLES. Antígona. Tradução de Millôr Fernandes. 8. ed. São Paulo: Paz e Terra, 2008.

SOUSA, André Lima. Fortaleza por um fio: O espaço de transição e o Movimento dos Conselhos Populares. 2011. Dissertação de Mestrado do Programa de Pós-Graduação de Geografia da Universidade Federal de Santa Catarina, 2011. 